Lecture Notes in Civil Engineering

Fabio Bianconi

Marco Filippucci Editors

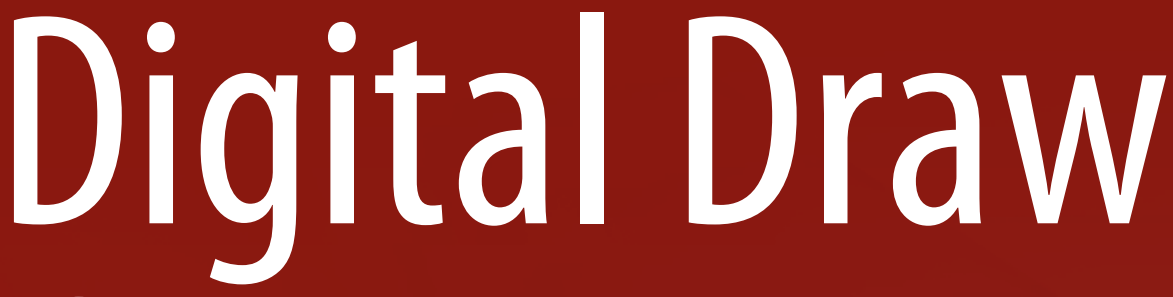

Connections

Representing Complexity and

Contradiction in Landscape

Springer 


\section{Lecture Notes in Civil Engineering}

\section{Volume 107}

\section{Series Editors}

Marco di Prisco, Politecnico di Milano, Milano, Italy

Sheng-Hong Chen, School of Water Resources and Hydropower Engineering, Wuhan University, Wuhan, China

Ioannis Vayas, Institute of Steel Structures, National Technical University of Athens, Athens, Greece

Sanjay Kumar Shukla, School of Engineering, Edith Cowan University, Joondalup, WA, Australia

Anuj Sharma, Iowa State University, Ames, IA, USA

Nagesh Kumar, Department of Civil Engineering, Indian Institute of Science Bangalore, Bengaluru, Karnataka, India

Chien Ming Wang, School of Civil Engineering, The University of Queensland, Brisbane, QLD, Australia 
Lecture Notes in Civil Engineering (LNCE) publishes the latest developments in Civil Engineering - quickly, informally and in top quality. Though original research reported in proceedings and post-proceedings represents the core of LNCE, edited volumes of exceptionally high quality and interest may also be considered for publication. Volumes published in LNCE embrace all aspects and subfields of, as well as new challenges in, Civil Engineering. Topics in the series include:

- Construction and Structural Mechanics

- Building Materials

- Concrete, Steel and Timber Structures

- Geotechnical Engineering

- Earthquake Engineering

- Coastal Engineering

- Ocean and Offshore Engineering; Ships and Floating Structures

- Hydraulics, Hydrology and Water Resources Engineering

- Environmental Engineering and Sustainability

- Structural Health and Monitoring

- Surveying and Geographical Information Systems

- Indoor Environments

- Transportation and Traffic

- Risk Analysis

- Safety and Security

To submit a proposal or request further information, please contact the appropriate Springer Editor:

- Mr. Pierpaolo Riva at pierpaolo.riva@ @pringer.com (Europe and Americas);

- Ms. Swati Meherishi at swati.meherishi@springer.com (Asia - except China, and Australia, New Zealand);

- Dr. Mengchu Huang at mengchu.huang@ @pringer.com (China).

All books in the series now indexed by Scopus and EI Compendex database!

More information about this series at http://www.springer.com/series/15087 
Fabio Bianconi · Marco Filippucci

Editors

Digital Draw Connections

Representing Complexity and Contradiction in Landscape

Springer 


\section{Editors}

Fabio Bianconi

Department of Civil and Environmental

Engineering

University of Perugia

Perugia, Italy
Marco Filippucci

Department of Civil and Environmental

Engineering

University of Perugia

Perugia, Italy

ISSN 2366-2557

ISSN 2366-2565 (electronic)

Lecture Notes in Civil Engineering

ISBN 978-3-030-59742-9 ISBN 978-3-030-59743-6 (eBook)

https://doi.org/10.1007/978-3-030-59743-6

(C) The Editor(s) (if applicable) and The Author(s), under exclusive license to Springer Nature

Switzerland AG 2021

This work is subject to copyright. All rights are solely and exclusively licensed by the Publisher, whether the whole or part of the material is concerned, specifically the rights of translation, reprinting, reuse of illustrations, recitation, broadcasting, reproduction on microfilms or in any other physical way, and transmission or information storage and retrieval, electronic adaptation, computer software, or by similar or dissimilar methodology now known or hereafter developed.

The use of general descriptive names, registered names, trademarks, service marks, etc. in this publication does not imply, even in the absence of a specific statement, that such names are exempt from the relevant protective laws and regulations and therefore free for general use.

The publisher, the authors and the editors are safe to assume that the advice and information in this book are believed to be true and accurate at the date of publication. Neither the publisher nor the authors or the editors give a warranty, expressed or implied, with respect to the material contained herein or for any errors or omissions that may have been made. The publisher remains neutral with regard to jurisdictional claims in published maps and institutional affiliations.

This Springer imprint is published by the registered company Springer Nature Switzerland AG

The registered company address is: Gewerbestrasse 11, 6330 Cham, Switzerland 


\title{
The Social Identity of a Place: The Analysis of the Environment and Its Quality for a Cultural Regeneration.
}

\author{
Silvia La Placa and Marco Ricciarini
}

\begin{abstract}
The man makes his way through the centuries armed with pencil: any mean capable of leaving a mark on a surface becomes the trace to be followed from generation to generation in order to know and explain the world. From the engraving on the stone to the digital image the line remains the instrument of comprehension par excellence. Graphic representation is the basis for cognitive processes and for social, cultural and sustainable redrawing of the places. The interaction between environmental psychology and architecture is configured in this sense as the best disciplinary framework in which to develop new models of representation of complex and contradictory realities, that put the human dimension at the centre. The integrated survey project "The sports locations in Tuscany", born following an agreement between the Department of Architecture of Florence and ANCI Tuscany (National Association of Italian Municipalities), opens the way to an examination of sports environments and to an interpretation that starts from the graphic sign. Problems of various nature emerge from the architectural survey, which have to be read together with the typology and the use of these centers. Their inclusive type nature is not in accordance with the current built-up forms in which they are forced: the expected educational, formative and identitarian environment is obscured by architectural inattention and insufficient maintenance [1]. The aim is to investigate the origins of this contradiction in order to retrieve a necessary balance between the contents and the container.
\end{abstract}

Keywords Reuso $\cdot$ Sign $\cdot$ Architectural survey $•$ Environmental psychology • Human dimension

\footnotetext{
S. La Placa $\cdot$ M. Ricciarini $(\bowtie)$

DIDA Department of Architecture of the University of Florence, Florence, Italy

e-mail: marco.ricciarini@unifi.it

S. La Placa

e-mail: silvia.laplaca@stud.unifi.it
} 


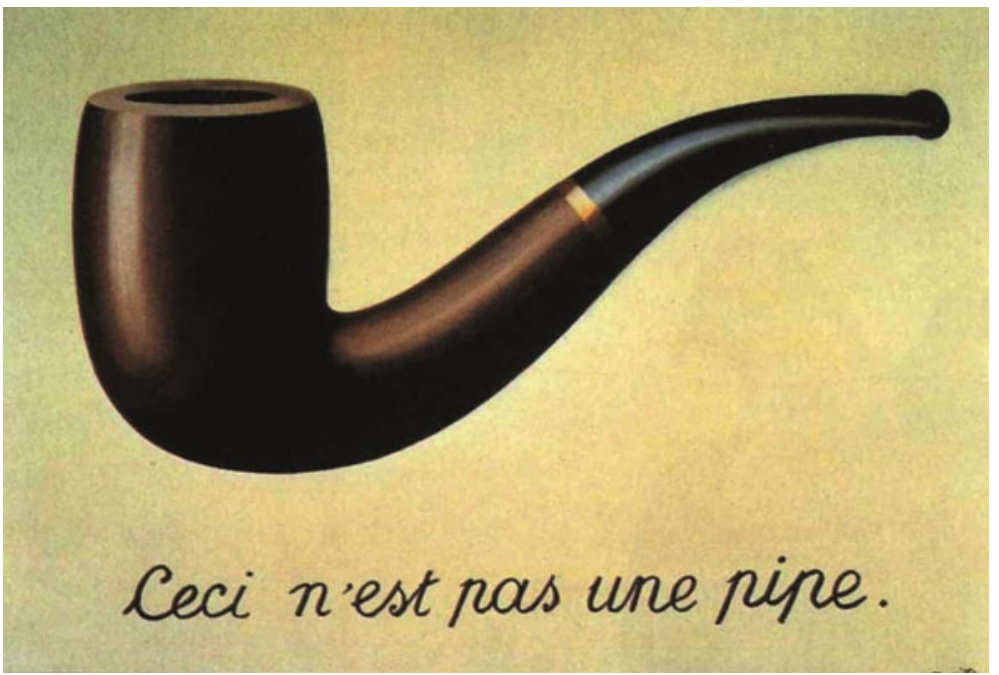

Fig. 1 The trahison des images painting by René Magritte, the difference between a physical and concrete object and its representation

\section{Introduction}

The architect is one of the most influential transformers of the natural world: he expresses the concepts of change and evolution in the only concrete form that anyone can read, namely freehand drawing, an essential synthesis for the creative act. The new digital technologies widen the possibilities also bringing significant changes to the representation and therefore to the communication that in fact links design and observer. The current era of image has made the visual element a primary factor for the individual and for society, without hiding the dual character of real or realistic reproduction [2]. Over the years, a world has developed that is parallel to the physical world, a virtual world, yet with an extremely concrete appearance, which holds the individual between what appears and what is physically suspended. This condition of limbo is not new, although the ways in which it is manifested are different: look at the post-Venturian Las Vegas, city of images per excellence, of what dazzles and attracts (and at the same time with greater vehemence it distracts). The image goes beyond the concept of written communication and immediately leaves the impression of truth to the observer, showing its structural complexity: on one hand, the desire to transfer real information makes it always more correct and truthful, on the other it creates a volute confusion between the true and the represented (Fig. 1). ${ }^{1}$

\footnotetext{
${ }^{1}$ See the painting This is not a pipe, 1948, by René Magritte. The author paints a pipe and writes in "this is not a pipe" paying attention to the relationship that exists between logical and analogical representations. What you look at is in fact the image of a pipe and not the real object. Thus Magritte gives rise to a reflection on the weak border between reality and representation. Michel Foucault, This is not a pipe, Publisher: SE, Edition year: 1988, EAN: 9788877101044.
} 
The debate that could arise from this statement is very broad, as Franco Purini argues in his A plural design: "if the representation is a simulacrum it is also, in itself, a reality. As a design, a drawing is a physical object, a body". That is, the representation has a dual character, being at the same time true and not true, yet we cannot help but use them to understand the space that surrounds us [3].

\section{Representation as the Basis of Cognitive Processes}

Architecture presents itself as a complex set of well-articulated physical elements in a unitary system that we could define as "plot". The drawing is the instrument capable of transposing the legible plot into reality on canvas, whether it be paper or electronic. It allows to know an artifact both before the work acquires physicality in the real, and after its construction, showing its design and figural sense. Drawing is the founding science of architectural discipline, the means by which it is possible to manage space, in its geometric and formal aspects, and communicate the meaning, the idea of the project [4]. The act of drawing implicitly contains the study of the place and the ways in which the professional compares himself [5]. Among the various and complex disciplines used in architecture, it certainly plays the role of a binder, facilitating memory and design expression. Through representation it is possible to grasp, investigate, solve the problems and complexities of places and territory, whether they pertain to their past, present or future. Also placing itself at the base of the work of many different specialists, from designers to urban planners to restorers, it becomes a necessary condition for communication and therefore a subject of study and approach to knowledge [6].

The American architect and theorist Robert Charles Venturi Jr. (1925-2018) was one of the main inspirers of the postmodern current in architecture, contrasting among the first with the dogmas of the Modern Movement. His theoretical work has had such an influence that today he creates the inputs to always face new cultural debates, at any scale. The two texts published by the architect of Filadeflia, Complexity and Contradiction in Architecture (1966) and Learning from Las Vegas (1972), initially earned him condemnations and criticism both from the United States and from Europe, but soon paved the way for other thinkers [7, 8]. The first essay opposes the geometries of the masters of the Movement, to the point of responding to the philosophy of "less is more", 2 by Mies van der Rohe, with the ideology of the "less is bore" phrase that crowns Venturi father of postmodernism.

Complexity and Contradiction in Architecture, published by Philip Johnson's MoMA, shows the connections between ancient and modern architecture: the American architect recovers and uses the story with ease, making reference to it for his theoretical and architectural works, but never showing it explicitly [9]. At the same

\footnotetext{
${ }^{2}$ Less is more. The definition, by Mies Van Der Rohe, invited to a design for functional and linear elements, free from "disorders", while Venturi with irony claims the opposite favoring the complex to the simple, the hybrid to the pure.
} 


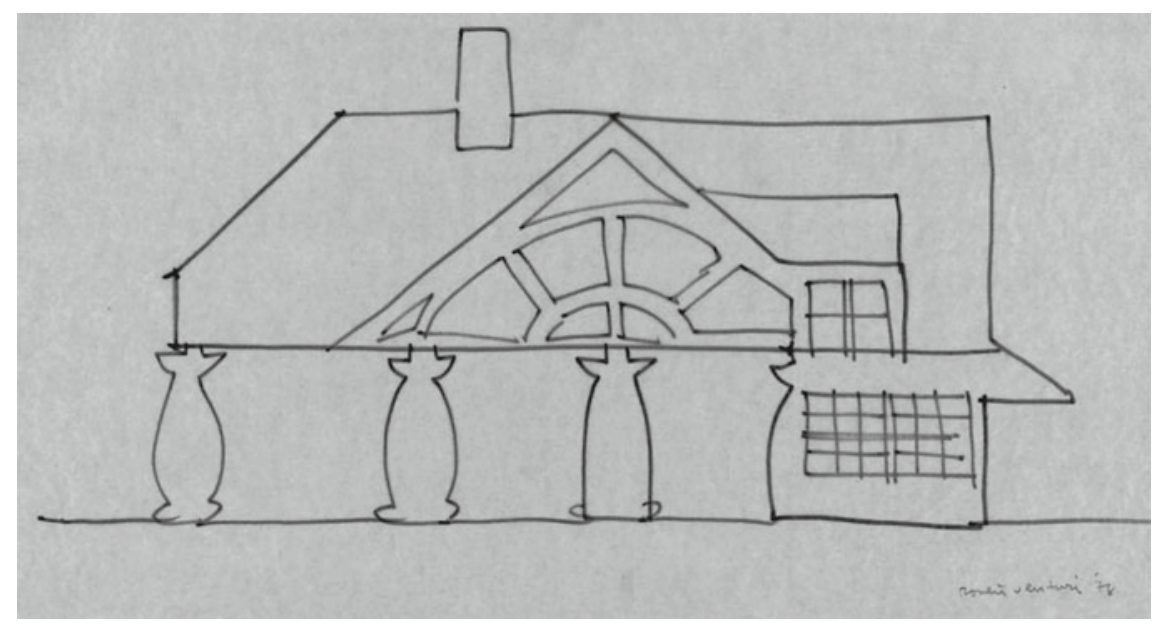

Fig. 2 Drawing by R. Venturi

time, Venturi's theory looks at and absorbs the incipit of English and American pop art: mass commercial products are exalted and symbols of national culture are massproduced [10]. While references to historical architecture are continuous, on the other hand the forms of tradition do not remain identical to themselves, but instead undergo a transformation: they lose their structural function and acquire a new, purely decorative and emphasizing feature (Fig. 2).

The "gentle manifesto", so defined by the same author, addresses a direct criticism of the last modern architecture, according to him as tired and now deprived of the first revolutionary ideas, inviting architects to look to the past and draw inspiration from the great European and American works in the different historical contexts. The strength of the book/manifesto lies in sanctioning imperfection, contradiction, architectural and urban complexity as resources, and no longer difficulties to be solved. Venturi opposes the simplification imposed in architecture by the masters of the Second World War, criticizing the modern movement for not having considered the plurality of architectural language, stopping at a neutral compositional typology. On the other hand, it is difficult to succeed in a unitary composition that embraces complexity: in his Venturi works he affixes symbols and decorations, restores their meaning to buildings, renewing the relationship of tension between the element and the context, enhancing the role of the structure starting from the its shape.

The second book, written together with Denise Scott Brown and Steven Izenour, proposes an absolutely innovative urban analysis, capturing the rapid and contemporary transformations brought about by the advent of the automobile. The architects documented and analyzed the city to give definition to the emerging urban form, with the aim of understanding it, managing it and adapting to it. Learning from Las Vegas overturns the typical dogmatisms of architectural history: the classic example loses exclusivity and every city becomes a fertile learning ground. In the text, Rome and Las Vegas are compared, not without creating scandal, because in both ways the good 
architect must know how to learn in different ways. For the first time the focus is on the change of scale, the essential symbolism in all environments, the places of mass, the everyday object: the city takes shape from nothing in a completely innovative way and the construction process deserves to this to be analyzed. The monuments of the past are replaced by advertising posters: what attracts visual attention are neon signs and large road signs. Signage information is the undisputed protagonist of the city of tomorrow, architecture becomes solely physical support, a means of information.

The text allows us to recognize and include popular American culture and especially its communication strategies. For example, the inclusion of objects registered in architectural works is not abolishing or criticizing, as was done until then, because we accept it because they are elements that respond to human needs and that communicate to man in regards to spaces and spaces.

Robert Venturi and Denise Scott Brown mark the passage from the architecture of function to that of communication: in the last texts Iconography and electronics on generic architecture [11] and Architecture as signs and systems: For a Mannerist Time (2004) emerges disinterest for architectural space and it is possible to grasp that one for communication and for a completely different type of architecture, a digital architecture (Fig. 3).

If the concepts of complexity and contradiction are linked to the landscape, it is possible to see how representation is sometimes not sufficient to capture the relational dimension that actually exists between man and context. This elusive complexity then requires a metamorphosis and a development of representative processes, which

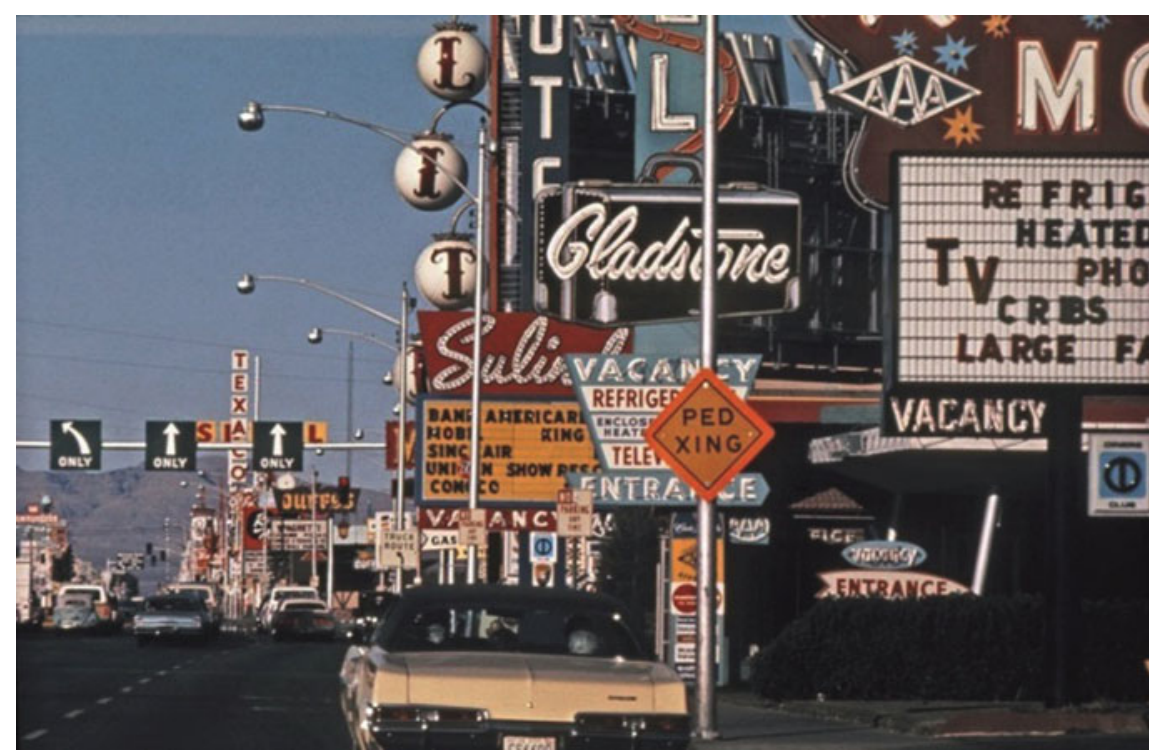

Fig. 3 Venturi with a research group studied various aspects of the city of Las Vegas, including commercial language, lighting, styles, and symbolism in architecture 
remain the main tools for understanding the environment and making its redesign possible. Contemporary culture lives the contradiction as a natural condition ${ }^{3}$ every aspect of reality always appears not perfectly irreducible precisely because of its complexity. The study of representation is the road that leads to the documentation and enhancement of the built, in the same way that the study of environmental psychology necessarily directs towards the recovery of the human dimension, an element to be placed again at the center of the current urban models. The joint experience of these two disciplines would allow a renewed approach to the concepts of urban accessibility and inclusive design, transforming architecture into an active expression of understanding and availability.

In the digital context, in which the contemporary individual is formed and acts, the representation assumes renewed importance according to the technologies that have significantly increased its declinations. Today the digital experience appears to be so immersive that it can be experienced as real: the systems identifiable in unison as Artificial Reality ${ }^{4}$ have redefined spaces and times of learning, offering increasingly rapid, effective communication models designed for a highly diversified audience [13]. In the same way in which in the passage from the oral tradition to the written one the recipient acquired greater possibilities of understanding and new capacities of interpretation, in the flow from the non-digital to the digital the final user enjoys enhanced faculties, arriving to interact directly with the representation.

Contemporary society constantly uses the image: the individual is wisely pushed towards one or another interpretation of reality, starting from descriptive contents specifically selected. Visual messages appear as the most appropriate type of communication to meet the needs and speed of everyday life. Images, more than words, facilitate understanding, simplify complexity, summarize concepts and at the same time measure themselves with growing scientific progress.

\section{Perceiving the Architectural Space}

Environment and Architecture permeate personal identity in an absolutely significant way and the topic is abundantly debated by psychological literature and yet it is unknown to most. On the contrary, it is clear to anyone that man is the being who more than any other has been able to change the environment, adapting it to his needs and transforming it through architecture. Today, and increasingly in the future,

\footnotetext{
${ }^{3}$ See Robert [12] Complexity and contradictions in architecture.

${ }^{4}$ As stated by the neuroscientist Stefano Baldassi (https://www.panorama.it/panoramaditalia-2017/ milano-2017/realta-aumentata-la-rivoluzione-e-piuvicina) the three-dimensionality of the objects arouses in individuals an emotional impulse: to reach a better understanding what they see they automatically tend to use the sense of touch. The representation of a good or a work of art through Augmented Reality systems allows the individual to sensorially implement the perception of that particular asset. The declinations for the AR (augmented reality) systems are many, among these also the possibility of making goods that no longer exist through the digital world or allowing the knowledge of works of art to categories with visual or hearing disabilities.
} 
attention must be paid to this concept, not only from an ecological point of view, an aspect not discussed here, but also from the point of view of daily well-being. It is therefore essential to rely on environmental psychology, a discipline based on human-environment dualism, to better understand and deal with the management of personal space as well as territorial behaviors.

Often in architecture we speak of "human dimension" of spaces "on a human scale"; these concepts, already studied in antiquity (think of the representation of the Vitruvian man by Leonardo da Vinci), have been taken up and deepened by the Modern Movement, which sees in Le Corbusier' Modulor their maximum expression. Today it seems necessary, in the light of the acquired knowledge, a reasoned design and that takes into consideration even some trivial mental situations in which people find themselves daily. In the study of light, for example, the architect will have to consider that this "increases the awareness of the presence of others (...) therefore in conditions of full light our interpersonal distances tend to be wider compared to conditions of darkness or semi-darkness", we must therefore bear this effect in mind depending on the purpose and the cut we want to give to the project.

We must consider now the concept of appreciability connected to height: in general this is associated with the status of dominance, therefore we tend to consider prestigious what is placed at the top. This psychological implication is commonly found in architecture and the building that develops vertically is, in fact, usually considered more pleasing to the eye, which is why it is often placed as a symbol of the city in which it is located (the towers of Bologna, the Tower of Pisa, the Eiffel tower in Paris etc.). Similarly, however, the elevated construction, imposing itself on the territory, can be highly disturbing if not aesthetically pleasing (telephone poles, antennas, etc.). In addition to light and height, it also deserves to focus on opening and closing spaces. Today open space is very much appreciated, both in homes and in workplaces (here it is called open office), because it gives the room more airiness and brightness, characteristics that are completely positive for the human mind. But a careful design should first of all be based on the needs of the people who will live in that particular environment:: here it becomes important for a large family to have a living area divided into several rooms, to allow each member to carry out their activities without being disturbed or disturbing for the others. Even more so in the workplace, keep in mind that, on the one hand, proximity to the colleague stimulates interaction between employees and production, on the other hand, in the long run the open office can be chaotic and a source of stress for those who live it daily. Usually the right answer can be found in the function for which a specific environment is designed. A further consideration is that one concerning the different psychological influences that urban environments have compared to rural areas: heat and noise, in addition to the aforementioned lighting, are also influential aspects of human behavior [14].

Deepening the relationship between the psyche and the architectural environment or the perception that one has of it therefore becomes a requirement in the context of a correct and careful planning. In recent years, psychology has assessed that the environment has a decisive influence on phenotypic and behavioral growth and development. Mario Costa, in his book Environmental and architectural psychology, brings as an example of the functioning of the human mind, compared to the change 
suffered by a given environment, that of the construction of buildings: "(... we tend to consider as attractive those (buildings) that are develop in height, rather than horizontally. The buildings that people visit the most in cities are in fact made up of cathedrals, skyscrapers, towers or in any case tall buildings. This derives directly from the fact that verticality, in our perceptive system, is "privileged" compared to horizontality. Even at the neuroatomic level there are more neurons in the sensory areas that selectively "discharge" in correspondence with vertically oriented stimuli compared to oblique or horizontal stimuli. "To simplify the concept, try to consider how the changes made to a certain environment indicate a certain psychology: the architecture of totalitarian regimes, for example, is characterized by rigid lines and solemn forms, because this kind of construction arouses in man a sense of oppression and at the same time of admiration. In Italy the association between spatiality and power took on great prominence in the years of fascism, because the great communicative capacity of architecture was captured, as had already been done in several previous periods/occasions.

When we talk about the link between architecture and psyche, however, we do not mean only those processes that are implemented starting from a situation of constructive concreteness, as in the case just mentioned. Often, even in an unconscious way, a series of behaviors is activated starting not from the place itself, but from the conception that one has of it. One can think trivially about the difference, in terms of time, that can be found in remedying the damage inherent in a public good and in a private good. In the first case the sense of responsibility is strongly attenuated, since this construction is conceived as "also of others" rather than as "of all" and therefore necessarily also ours. This is the reason why community management' architectures often involve far worse states than private ones. Here is how a knowledge of environmental and architectural psychology is able to open eyes to some issues, and allows to work in this direction.

In the perception of architectural space the aesthetics of the landscape play a key role: in relation to this Steven Kaplan and Rachel Kaplan have studied a complete psychological model, divided into four categories according to which the human being is led to evaluate the attractiveness of a environment. Consistency, Readability, Complexity and Mystery, these are the four most cherished features in a place, whether built or not, and therefore these are the ones that should be recreated by the architect. A shared experience is also the positive consideration of architectural and urbanistic disorder, compared to the order. Man is pleasantly struck by curved and hilly roads, rather than by straight roads; from stone facades and not from plastered, from a pattern in the pavement and not from the asphalt. Even these precautions contribute, where possible, to a better and more pleasant stay of the person in a given context. A more specific concept, always linked to functionality and therefore to design linked to the purpose, is that of affordance.

The term was introduced by J. Gibson in 1966, to indicate the ability that an object, especially a piece of furniture, has to immediately transmit its function to the viewer. A classic example is the anti-panic handle: the person in front of you has the impression of having to push it to open the door and not having to pull it, so that the handle has (necessarily, for safety reasons) a excellent affordance. It is therefore of 

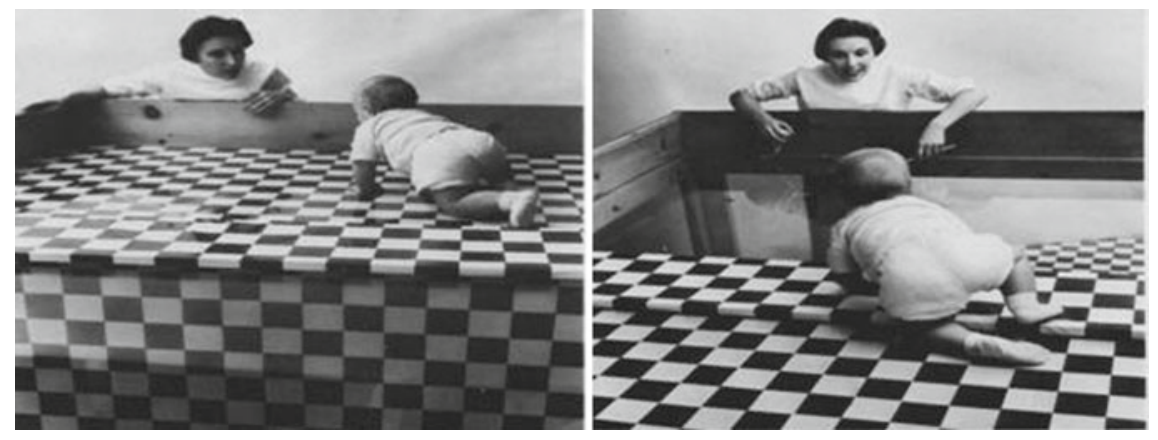

Fig. 4 An affordance is a relationship between an object or an environment and an organism, that affords the opportunity for that organism to perform an action

significant importance for the architect to consider these aspects in the design phase, if you do not want to incur the risk of seeing your furniture, urban or not, used in alternative ways to the expected ones (Fig. 4).

If we now consider the question of architectural perception from a broader point of view, we could cite many literature that deals with aspects of urban living in a more or less scientific and psychological way. Particular attention is paid to space studies and functional architecture, or rather to the planning guided by architectural psychology, we find it exhaustively in projects concerning these three main public environments: hospitals and facilities for the elderly, scientific institutions (libraries and schools but also museums and science parks) and religious places. Some buildings of public importance are therefore designed so that their use is optimized and consequently a greater user satisfaction is achieved. Moreover, public institutions often play a multidisciplinary role, so it is very important that their design makes them adaptable and flexible in spaces and functions.

As regards hospitals, it is worth mentioning briefly the work of the Finnish architect Alvar Aalto for the Paimio sanatorium. Particular attention to the perceptive aspect of the user of the work, earned the architect's style the title of "psychological functionalism". In the sanatorium project, being aware of the beneficial effects of solar radiation on patients, Aalto directed and related the various buildings in such a way as to maximize the benefits for therapeutic purposes. The hospital rooms were located to the South, the rooms intended for afternoon activities to the West, following the astral path of the sun and exploiting the advantages of heliotherapy. At the center of the Aaltian architectural survey, in fact, there has always been the need to make men feel good. Take, for example, the individual hospital rooms: each room could accommodate two patients, had special windows and radiant panels to ensure proper lighting of the room and preserve its healthiness and was surrounded by perimeter walls that were effective both in terms of color and sound absorption. The furnishings of the rooms were also oriented to the real needs of the patients, such as the sinuous chairs, able to adhere easily to the human body and, above all, a special sink that was carefully inclined so that the noise of the water was almost 
completely absorbed. On the sanatorium he himself said: "The primary purpose of the building is to function as a medical instrument ... One of the basic requirements to heal is to offer complete peace .... The design of the rooms is defined according to limited strenght of the patient, lying in bed. The color of the ceiling is chosen to give tranquility, the light sources are outside the patient's visual field, the heating is directed towards his feet and the water comes out of the taps without making noise, so that no one can disturb the room mate".

The situation is different in the design of libraries, whose primary purpose is the dissemination of culture. To encourage their attendance it is necessary that they become a place of stasis and no longer a passage. If one enters the library only to take and report volumes, there are no social interactions and one is not encouraged to return. It is therefore necessary to design the environment to make it comfortable and suitable for permanence, with some rooms designed for to study, with specific lighting and sound insulation specifications, others for conferences, with different solutions regarding the diffusion of sound and others still used to socializing spaces. It is important, as the library is a place of culture, to equip it with modern electronic systems, as well as areas suitable for computer processing. A good example in this sense, although not canonical, is Toyo Ito's media library in Japan.

The importance of psychological planning is clearly manifested in the creation of new religious places. In fact, in the construction of contemporary churches or synagogues, the majesty of ancient examples is no longer sought, but rather the sacred themes that each of the faithful carries within him are to be re-proposed through architecture. Imagine then an enveloping architecture, with studied lights, which gives a sense of sacredness but remains of human dimensions. In this case, architectural psychology invites the creation of a family environment. Particular attention must be paid to the aspect of acoustics, since it is necessary that all the faithful clearly hear the preacher, but that there is also silence in moments of recollection.

Excluding the three cases mentioned above, buildings are generally considered objects in their own right, rather the concrete elements of which our bodies and our neurological systems are strongly connected. The neuroscientist Mallgrave in his writings broadly explains how architecture is not a conceptual abstraction but an embodied practice, even believing that in architectural space it is constituted primarily through emotional and multisensory experiences. If we consider that current scientific discoveries ensure benefits also in the biological or psychological field, it can be considered possible that these same discoveries are able to improve the built environment. Mallgrave intends to direct the attention of architects and engineers towards those for whom it is designed: at the base of the design must be the future users. Theory that is supported by his study on the implications of neuroscience in architectural design [15].

"We shape our buildings, which in turn form us." These are the words of Winston Churchill, at the dawn of the reconstruction carried out after the Nazi bombings, and in these we find the importance of the way we feel and perceive, for the anthropic function, in its urbanization process. It is necessary then, also here, to reiterate the importance of doing good architecture, understanding the decisive influence that the built environment has on emotional states. 
Both architecture and psychology deal with the notion of "space", but the first does so by analyzing the external physical environment, the second by studying the inner psychic environment and also the interpersonal one. However, the boundary between outer and inner spaces is very weak and so these two disciplines end up getting closer. "There are no only material constructions; there are no only abstract thoughts", the cities tell historical and therefore human events, they are marked by aspirations and fears and equally mark their inhabitants. Thus, architecture ends up being immersed in places that are not only material, but also emotional, and for having to question what human needs are and what is the best way to satisfy them [16]. Different theoretical approaches connect, in the psychological sphere, the physical space to the psychic and psychosocial dimensions. The importance, in the formation of an individual, of his relationship with the surrounding environment is widely theorized. This, if favorable and stimulating, facilitates the psychic growth of the person and the development of maturity. The built space, as an environment, carries out more "mental functions": the containing one, performed by the familiar environments that make the individual feel protected; the sustaining one, to support the subjectivity and personalization that everyone implements in the places where he spends time; and the integrative one, which allows the encounter with the senior citizens. If the theories on the link between psychology and architecture are numerous, the discipline that regulates them has not yet become established on a large scale, although it has been officially institutionalized since the late 1950s. Psychologists and architects, moved by the interest in the study of the anthropic component of physical environments, have in fact started in those years an autonomous disciplinary sector to analyze the relationship between man and the built environment, and consequently produce applicative indications and architectural psychology was born.

A fundamental figure is that of Kevin Lynch, who already pioneered in the 1960s the need for psychology research to be carried out before the design of any building. In particular, his research highlighted the importance of way finding in living an urban fabric. According to Lynch, the ability to orient is in fact the ability of the inhabitant not only to know a territory, but also to have established mental connections that make it unique. This and other studies have contributed over time to ensure that the architectural environment was no longer considered a mere social living scenario, but an active and constitutive component of the human experience. The built space must then necessarily respond to human needs, otherwise we will face a situation of environmental stress, a concept that indicates a real discomfort but at the same time perceived. It includes physical elements such as noise, pollution or temperature, objectively measurable, but also relational factors such as the perception of too much crowding or insecurity. It incurs environmental stress when there is a low quality of the man-environment relationship.

Dedicating attention to the psychological variables in the design of the built space means understanding the psychic, symbolic, emotional, relational and needssatisfying functions that particular architecture will have on future users [17]. 


\section{From the Graphic Sign to the Psychological Interpretation: An Integrated Relief Project for Sports Facilities}

The greatest attention given to sport in recent years is triggering social change in the community. The interconnections linked to this area are today a positive tool for the training and long-term success of young people. The places assigned to physical activity and the growth of the individual, through the fascination generated by sports action, act as catalysts for community change. In Italy, more than elsewhere, it becomes necessary to face some challenges and overcome the structural, distributional and fruition problems that, despite the positive propulsion of the last few years, remain in sports facilities. ${ }^{5}$

Architectural research is the tool through which to make valid contributions to the achievement of this aim. The DIDA Department of Architecture of the University of Florence has, for some years, been promoting the testing of a methodology of analysis and study that can redevelop the plant and generate social change in the sports field. In order to reach a qualitative level of the amateur centers in line with the major European directives, ${ }^{6}$ an awareness-raising process was undertaken aimed at operators in the sports world, to make the critical points known and systematically addressed.

A first synergy with Federciclismo Toscana and Federcalcio Toscana saw the DIDA engaged in the research project "Kick Away Spaces of Tomorrow"7 : the documentation collected (from the three-dimensional survey, to the management files) made it possible to assess the actual state of the art of 20 amateur centers present on the Tuscan territory and to have a consolidated work base to carry out redevelopment projects (some already undertaken by sports clubs involved) (Figs. 5 and 6).

The project, born from the conviction that places of growth should make an important contribution to the definition of quality, starts from the assumption that great weight in relationships and in the symbiosis of the user with the environment is to be attributed to the perceptive evaluation that the latter has of the sports facility. As positive actions, at the educational and personal interchange level, they generate enrichment in the individual, in the same way an inhospitable environment leads to non-educational behavior. It therefore appears necessary to approach a place from the structural, aesthetic and material, but also psychological point of view. The design methodology foresees this double attention, addressed both to the environment and to

\footnotetext{
${ }^{5}$ See THE SPORTS NUMBERS 2017 drawn up by the CONI Services Center for Statistical Studies and Observatories for Sport, in December 2018 and the FGCI Football Report 2018 drawn up by the FGCI and PwC Study Center for financial aspects.

${ }^{6}$ See EUROPEAN COMMISSION White Paper on Sport and International Charter for Physical Education, Physical Activity and Sport edited by UNESCO since 1978.

${ }^{7}$ See Stefano Bertocci, Silvia La Placa, Marco Ricciarini, The recovery and enhancement of sports facilities in the urban redevelopment process. Conference Proceedings Colloquia.AT.e 2019. Engineering and Construction in the Age of Complexity Turin, 25-28 September 2019.
} 


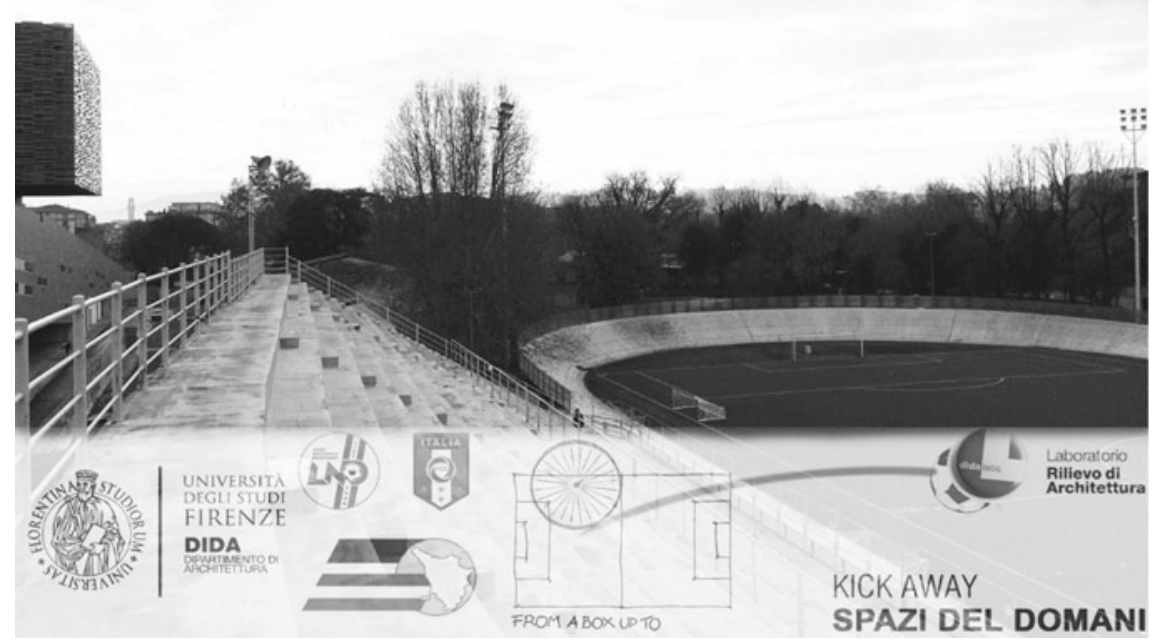

Fig. 5 Introducing the research project Kick Away Spazi del Domani

the relation modalities that exist among its users. The aim is to understand the prerequisites for achieving a person-environment relational balance in the sports field: to be able to design places that positively stimulate the performance of the professional athlete and the psychophysical development of the growing young person.

For this reason, DIDA has promoted the study of the Coverciano sports center of excellence, which comes very close to the aforementioned equilibrium condition. The analysis of the Luigi Ridolfi Federal Technical Center ${ }^{8}$ followed the same operational methods applied for the "Kick Away Spaces of Tomorrow" project, but coming to a level of detail, for Coverciano, much more in-depth, since it is a single complex and an example to follow for the redevelopment of sports facilities. The first phase saw the study and distribution analysis of the spaces: a management database was created that allows, through filing made with a filemaker program, to know every part of the complex at different levels (dimensional, material, management, functional, distributional, energetical etc.). Subsequently, on-site analysis was carried out, using laser scanner equipment and photographic equipment, and this made it possible to carry out a third computerized post-production phase (cyclone, 3Dflow, AutoCAD). Research has shown the connection between valid architectural design for sports facilities and the social relationships that take place within it. The dissemination of the results achieved through both projects leads to an awareness on the subject by amateur centers that today do not reach high quality levels but intend to pursue them (Fig. 7).

\footnotetext{
${ }^{8}$ See the Thesis in Survey of Architecture entitled "The Federal Technical Center of Coverciano an architecture for sports education", La Placa S., Martini B. Relator Professor S. Bertocci, Coordinator Arch. M. Ricciarini.
} 

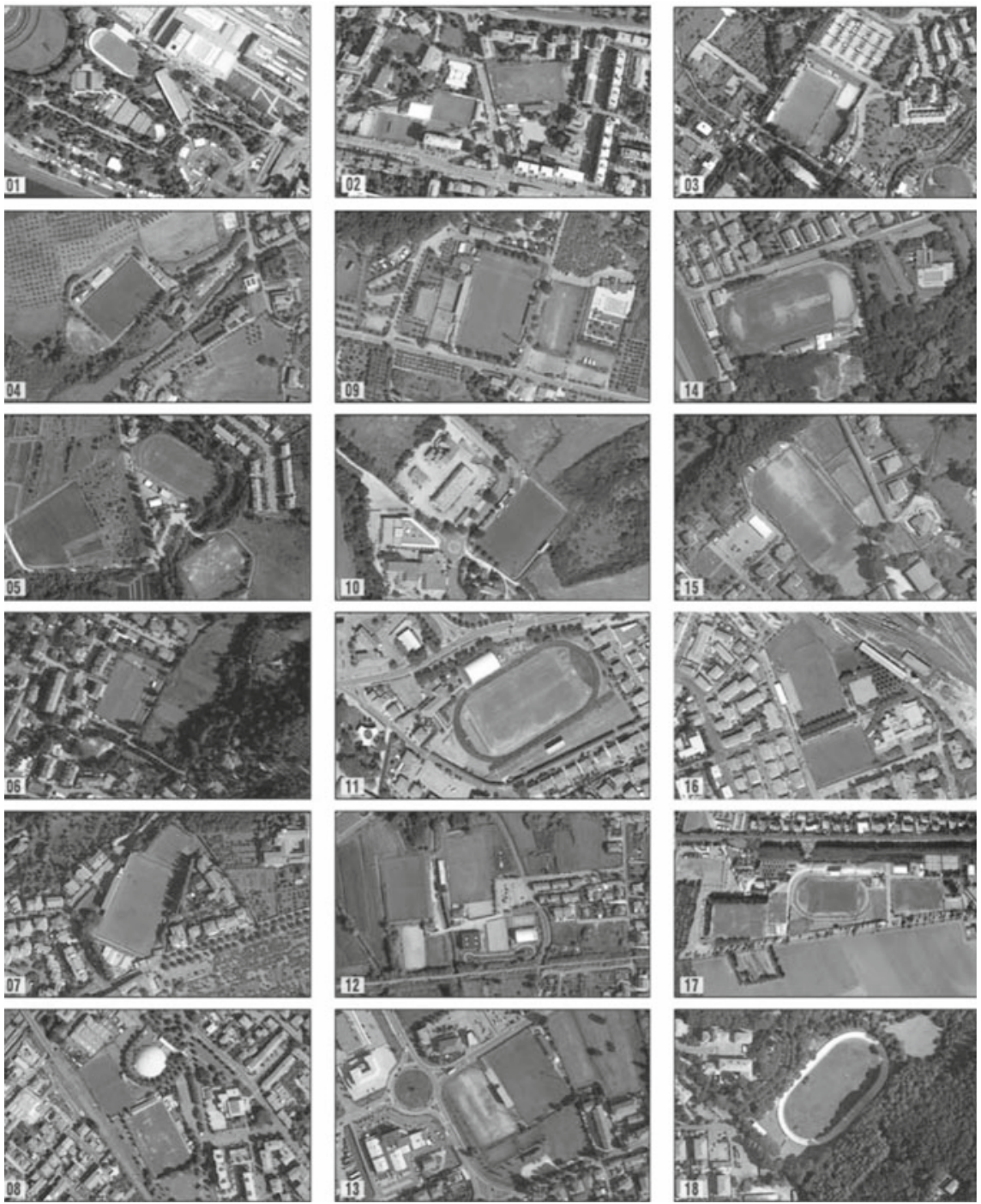

Fig. 6 Regional sports facilities analysed during the research period

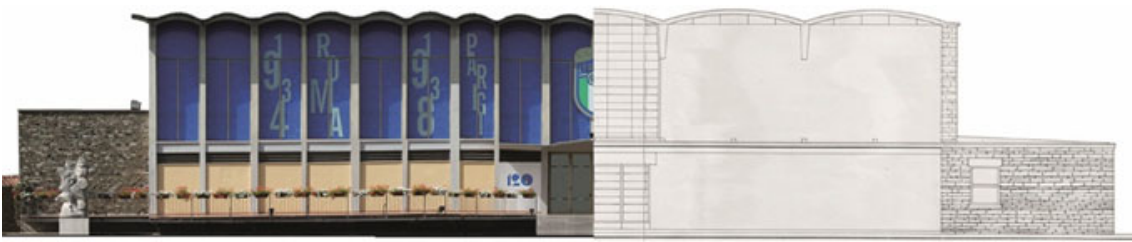

Fig. 7 Comparison of the original project graphs and the representation of the current state of fact of the gym of the Federal Technical Center of Coverciano 


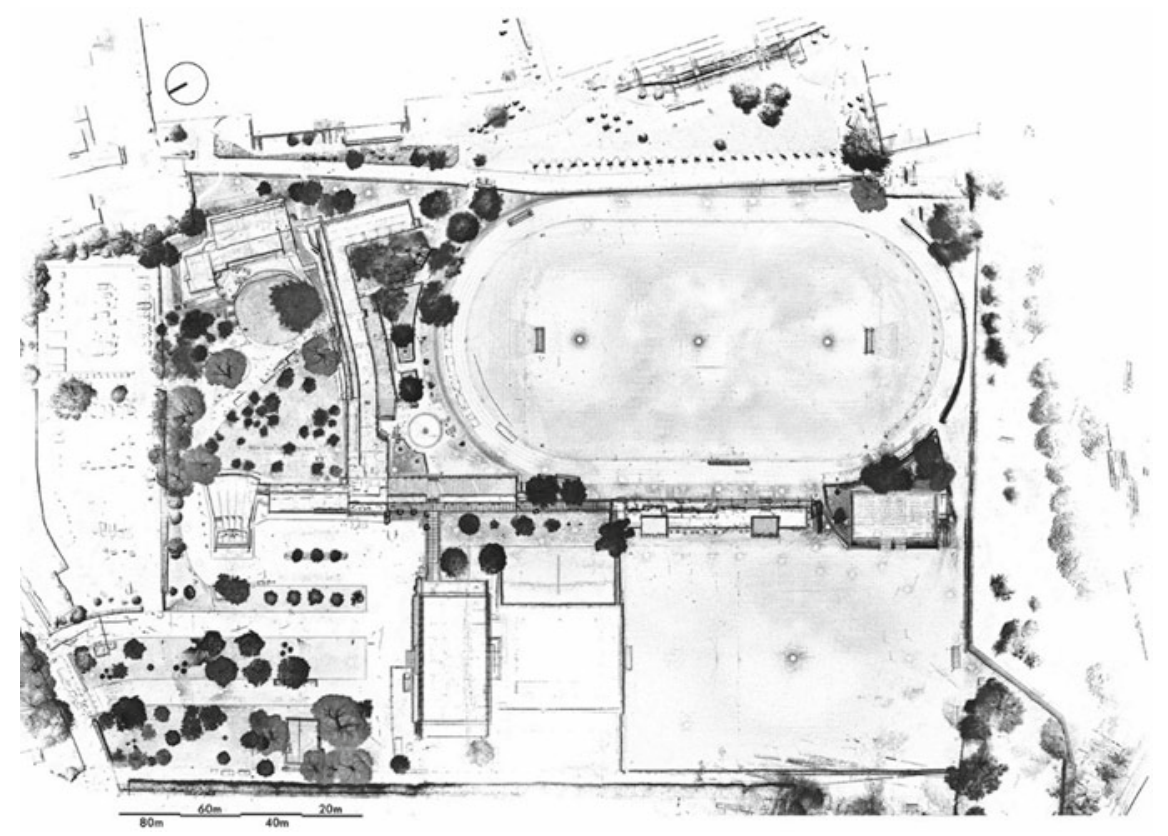

Fig. 8 General plan of the Federal Technical Center obtained from the processing of the point cloud

Research into sports venues also allows for a broader analysis to be initiated, as many of the amateur sports facilities arise marginally from the city, in peripheral urban fabrics, becoming new unexpected aggregation nuclei. If considered in the complexity of urban and suburban macro-areas, they are among the most significant social infrastructures: they are today the substitutes for the public park, the square and the oratory. These are meeting places that incur, due to their position and architectural inattention, in the risk of becoming non-places ${ }^{9}$ in a short time, in which young people become accustomed to withering rather than growing. Such considerations, on an architectural, urban and social scale, arise from a careful analysis of the territory and are possible starting from the interpretation of the legible graphic sign in such complexes [18]. Here, drawing and architectural survey are of fundamental importance, disciplines necessary to be able to initiate interventions of transformation of structural and perceptive quality (Fig. 8).

The Department of Architecture of the University of Florence, together with the Regional Social Sport Observatory of the Tuscany Region and ANCI of Tuscany, is currently engaged in a research project that leads from architectural analysis based on design and survey to a perceptive improvement of the user of all the Tuscan amateur sports centers. The Relevant Laboratory of the DIDA Department of Architecture of the University of Florence intends to learn about and analyze regional amateur

\footnotetext{
${ }^{9}$ See Mello Patrizia, Metamorphosis of space. Annotations on the metropolitan becoming.
} 
sports facilities. The study of the architectural state of affairs, an essential basis for implementing maintenance and improvement programs for the centers, allows to evaluate not only the structures themselves, but also the different ways in which the materiality of these generates specific relationships in the community.

The project highlighted the multiple and complex interactions between static and dynamic components of the city system (school, sports, cultural activities, commercial activities, etc.) highlighting the massive presence of containers and spaces with functions directly or indirectly related to sports activities, in need of intervention. This is due to the fact that the Italian architectural sporting heritage can be dated almost without exception to a period of time that goes from the post-war period to the 1990s. The realization of the structures in this limited time range is the result of the corporate change imposed on the great industrial transformations produced by history [19]. Two events in particular have marked the national territory in this sense: the Rome Olympics in the 60s and the awarding of the World Cup for football, officially announced in $1984 .{ }^{10}$ "The World Cup will be the most opportune occasion to demonstrate not only our organizational skills, but also the high technological level reached in all sectors of national life" ${ }^{11}$ : this is how Franco Carraro, president of the Organizing Committee of Italia 90 expressed himself. In Italy, therefore, we witnessed a modernization of the plants, most of which dated from the 1930s, soon degenerated into a long procession of public sports infrastructures lacking precise planning within the urban fabric, as well as of little architectural value. Administrations today find themselves having to manage structures that are often left unfinished and the one who pays the costs of this condition is the citizen [20].

"The places of sport for Tuscany" is a multi-hand work which involves the research and development of analysis, requalification and support projects for the design of sports facilities, to be held for the Municipalities of the Tuscany Region starting from January 2019 [21]. The aim of the project is to translate the dimension of research into development opportunities for the entire regional territory: the sharing, by the entities involved in the project, of diversified strategies for each type of plant allows identifying concrete actions to favor the process of redevelopment of each, whether relating to school, recreational or amateur motor activities. Collaboration with sports associations, aided by the dissemination of research activity, is enabling a constructive dialogue with Public Administrations and offering a better service to the community (Fig. 9).

The "Places of sport for Tuscany" project promotes innovative study guidelines for sports facilities, embracing the current issues of energy saving (the use of new materials for construction and the implementation of greater efficiency is

\footnotetext{
${ }^{10}$ See Nicola Adduci, Francesco Bonini, Annabella Gioia, Italo Insolera, Francesca Mazzarini, Roberta Sibbio, Bruno Tobia, Leopoldo Tondelli "The Olympics of the" miracle "fifty years later" the 1960 Rome Olympics, a significant appointment, only fifteen years from the end of the Second World War, which showed a growing, regenerated and in full economic miracle. An event that is re-read in the light of an intertwining of sports history, political-institutional history and urban history.

${ }^{11}$ See https://storiedicalcio.altervista.org/blog/mondiali-1990-germania.html.
} 


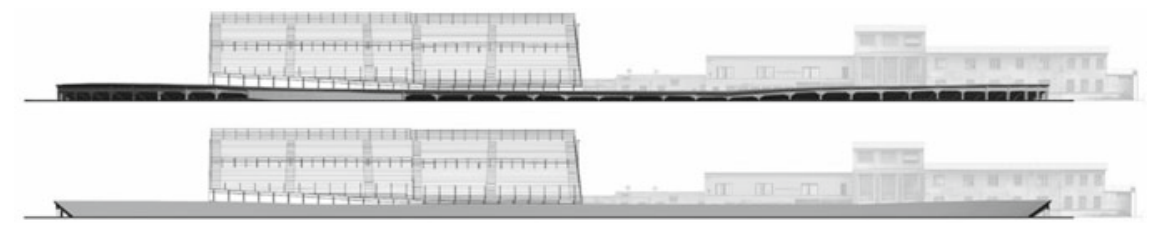

Fig. 9 Environmental section of the ultra-centenary sports facility of the Park of the Cascine in Florence

proposed energy efficiency of the plants), safety and the elimination of architectural barriers, respecting the right of all to sport. ${ }^{12}$ A path of support has been prepared — for the energy, technical-economic and administrative areas-in favor of local Administrations who will enjoy the support of the Department of Architecture.

\section{From Urban to Social Analysis}

Robert Venturi's studies invite an analysis that goes from urban to social and vice versa, showing how these two aspects are inextricably linked. "Tending towards difficult unity"13 calls for a consideration of the global landscape, which also covers socio-cultural aspects and embraces contemporary issues and challenges [22]. The different urban realities are synonyms of identity of each specific social situation, which is consequently perceived (and at the same time derives) from its inhabitants. In the case study presented, along with the type and use of sports centers, various problems have emerged from the architectural survey. The inclusive nature of these places is difficult to reconcile with the current built-up forms in which they find themselves forced: the expected educational, training and identity environment is obscured by architectural neglect and insufficient maintenance. The research experience, innovative from the point of view of the subject addressed, aims to focus on the contradiction expressed by sports architecture and does so through the increasingly immediate tool: drawing. The representation allows to explain in a clear and synthetic way a given reality showing, starting from the graphic restitution of the architecture, also all the immaterial connections that are its foundation. The images therefore rise (and have always been) to a fundamental role: today more than ever they are requirements for understanding, both because digital is the filter through which the world is looked at, and for the speed with which more and more we are accustomed to confront. Impact is what is easy and immediate at the same time, the image more than text, digital more than paper [23].

\footnotetext{
${ }^{12}$ See the EUROPEAN SPORT CHARTER of the COUNCIL OF EUROPE CDDS-Committee for the Development of Sport 7th Conference of European Ministers responsible for Sport Rhodes, 13-15 May 1992.

${ }^{13}$ See Robert [12] Complexity and contradictions in architecture.
} 
However, it is not just an aesthetic issue that defines the direction towards the architectural survey for sports facilities: the analysis, the study and the measurements allow to make a real improvement to these structures, from the structural, economic, managerial and perceptive point of view [24]. The development of a suitable integrated survey methodology makes it possible to obtain-through multiple tools and computerized post-production-a quantity of diversified and comprehensible data at multiple levels, from final users, administrations and sector operators. The digital reconstructions, which are obtained starting from the mixture of the laser scanner and the photogrammetric survey, make it possible to have $3 \mathrm{D}$ models at a high level of precision. Each model can then be developed according to the final use: for visualization/documentation only, for material management, plant engineering, for the identification of internal paths, etc. Digitally re-proposing the built finds its greatest value primarily in the ability to communicate (and therefore making it accessible and known) a specific architectural typology ${ }^{14}$ and this becomes in some way tangible even at distance.

The declinations and the possibilities that open up starting from the image are many and always to be compared to the scale of representation on which one is operating: an urban scale modeling certainly has different purposes than one in detail; starting from the first, for example, it is not possible to imagine a structural restoration. Despite the complexity-defined starting from the specificity of each architectural or urban typology - the image is in any case the most appropriate interpretative act for each spatial form, from the concrete to the designed [25]. Processing a representation therefore requires a prudent procedure, in which it is first of all defined an ordered sequence of operations which, from the acquisition phase, leads to the most effective product to be published. The potential of digital representation technologies (such as those based on photographs) allow the punctual reproduction of the object under study, conferring the consequent advantage of a documentation that is as precise as it is declinable [26]. The cognitive survey qualitatively investigates the heritage built in three successive phases, which can in turn be divided into subsets: the acquisition, processing and publishing of the data obtained. These operations require specific technical skills as well as continuously updated and consequently require a preliminary study, which knows how to direct the operator to the most appropriate image processing.

\section{Conclusions}

The design of concrete architecture has been integrated over the years with a different design, which almost never considers the territory, rather it erases the traces, attracted by the spaces without limits offered by information technology. A finished place to relate disappears, in favor of a virtual world that seduces by imaginative freedom.

\footnotetext{
${ }^{14}$ Gaiani, M., Architectorum delineamenta instrumenta or the architect's work interfaces, in Unali, M., (edited by), "Virtual living means to represent", Kappa, Rome 2008.
} 
The consumption of images in the architectural field is due to the too wide gap that exists between the simplicity and immediacy of a slogan (see Learning from Las Vegas) and the complexity of constructing a technical design that is at the same time aesthetically valid. Nevertheless, complexity is today enhanced, resulting in a vibrant aspect of the contemporary, precisely because of the many roads still unexplored and the great expectations in the field of computer technology [27]. Perhaps a renewed balance for our architecture and city should be sought in the mix of technique and aesthetics typical of digital design?

\section{References}

1. Luigini A (2018) Ambienti digitali per l'educazione all'arte e al patrimonio. Franco Angeli editore, Milano

2. Jenkins H (2009) Culture partecipative e competenze digitali. Media education per il XXI secolo. Guerini, Milano

3. Foucault M (1988) Questo non è una pipa. SE, Milano

4. Paris L (2011) La rappresentazione originale. In: Artefatti, Idee per la rappresentazione, a cura di AA.VV. Atti del seminario di studi tenutosi a Perugia il 20.11.2009. Artegrafica, Roma

5. Purini F (2003) Un disegno plurale. In: "Firenze architettura", periodico semestrale del Dipartimento di Progettazione dell'Architettura, numero doppio (maggio 2003), pp 53-67

6. Norman D (2010) Living with complexity. MIT Press, Cambridge, Massachusetts, Stati Uniti

7. De Vivo EA (21 settembre 2018) In memoria di Robert Venturi. [Blog Post]. Retrieved from https://www.artribune.com/static-index.html

8. Orazi M (21 Settembre 2018) Cosa possiamo imparare da Robert Venturi. [Blog Post]. Retrieved from https://www.rivistastudio.com/robert-venturi/

9. Redazione Youmanist (19 Novembre 2018) Robert Venturi: il bello della complessità. [Blog Post]. Retrieved from https://youmanist.it/categories/architettura-design/modernismo-robertventuri

10. Venturi R, Scott Brown D (2004) Architecture as signs and systems: for a mannerist time. The Belknap Press of Harvard University Press, Cambridge, Massachusetts

11. Venturi R (1996) Iconography and electronics upon a generic architecture: a view from the drafting room. MIT Press, Cambridge

12. Venturi R (1980) Complessità e contraddizioni nell'architettura. Dedalo, Bari

13. Krueger M (1983) Artificial reality. Addison-Wesley, Boston

14. Grecchi M (2008) Il recupero delle periferie urbane. Da emergenza a risorsa strategica per la rivitalizzazione delle metropoli. Maggioli Editore, Rimini

15. Rivoltella PC (2014) La previsione. Neuroscienze, apprendimento, didattica. Editrice La Scuola, Brescia

16. Balzani M (2017) Spazio intersecato: Percorsi di confine e tematismi di aggregazione per il rilievo, la rappresentazione e il progetto. Santarcangelo di Romagna (RN). Maggioli editore, Italy

17. Lanier J (1992) Virtual reality: the promise of the future. Interactive Learning International 8(4):275-279

18. Ardita VM (2008) Nuovi Scenari di Progetto/nuovi luoghi per la città contemporanea. Università degli Studi di Catania

19. Arnaboldi MA (1982) Atlante degli impianti sportivi. Hoepli Editore, Milano

20. Gottfried A (2004) L'edilizia per lo sport e lo spettacolo. Quaderni del manuale di progettazione edilizia. Hoepli Editore, Milano

21. Culley P, Pascoe J (2009) Sports facilities and technologies. Routledge, London 
22. Bortolotti A, Calidoni M, Mascheroni S, Mattozzi I (2008) Per l'educazione al patrimonio culturale: 22 tesi. FrancoAngeli, Milano

23. Brilliant R (1987) Narrare per immagini. Giunti, Firenze

24. Gratton C, Henry I (eds) (2002) Sport in the city: the role of sport in economic and social regeneration. Routledge, London

25. Purini $F$ (2007) Una strategia possibile. In Idee per la rappresentazione, atti del seminario di studi, Roma 14 settembre 2007, a cura di Fabio Quici. Form.Act editore, di Fabio Quici

26. Balzola A, Monteverdi AM (2004) Le arti multimediali digitali. Storia, tecniche, linguaggi, etiche ed estetiche delle arti del nuovo millennio. Garzanti, Milano

27. Carpenzano O (2012) Idea immagine architettura: Tecniche d'invenzione architettonica e composizione. Gangemi Editore, Roma 


\section{Dichiarazione stesura paragrafi del contributo}

I sottoscritti:

Il Dottore di Ricerca Marco Ricciarini nato a Prato in Provincia di Prato, il 17/06/1979 residente a Cervia in Provincia di Ravenna, in Via Delle Azalee, 25;

L'architetto Silvia La Placa nata a Firenze in Provincia di Firenze, il 23/08/1993 residente a Prato in Provincia Prato, in via Bernardo Buontalenti, 3;

consapevoli delle sanzioni penali in caso di dichiarazioni false e della conseguente decadenza dai benefici eventualmente conseguiti (ai sensi degli artt. 75 e 76 D.P.R. 445/2000) sotto la propria responsabilità

\section{DICHIARANO CHE IN MERITO AL CONTRIBUTO DAL TITOLO}

\section{THE SOCIAL IDENTITY OF A PLACE: THE ANALYSIS OF THE ENVIRONMENT AND ITS QUALITY FOR A CULTURAL REGENERATION.}

il Dottore di Ricerca MARCO RICCIARINI è l'autore dei paragrafi:

\section{- 1 Introduction;}

- 3 Perceiving the Architectural Space;

- 4 From the Graphic Sign to the Psychological Interpretation: An Integrated Relief Project for Sports.

l'architetto SILVIA LA PLACA è l'autrice dei paragrafi:

- 2 Representation as the Basis of Cognitive Processes;

- 5 From Urban to Social Analysis.;

- 6 Conclusions..

I sottoscritti dichiarano inoltre di essere informati, ai sensi del D.Lgs. n. 196/2003 (codice in materia di protezione dei dati personali) che i dati personali raccolti saranno trattati, anche con strumenti informatici, esclusivamente nell'ambito del procedimento per il quale la presente dichiarazione viene resa.

Firenze, 19 maggio 2021

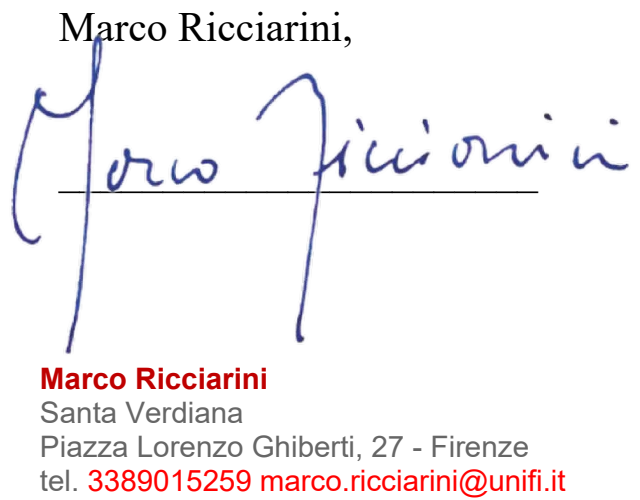

Silvia La Placa

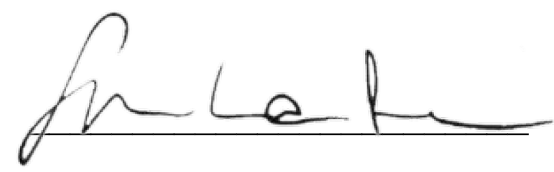

